\title{
Noradrenaline and attention lapses Nomenclature
}

SIR - States of low alertness, produced by factors such as sleep deprivation, decrease performance on tasks of sustained attention. This is manifest by increases in the number of very long reaction times or in failures to respond. The effect can be reduced by increasing alertness by, for example, exposing the person to loud noise ${ }^{1}$.

Although arousal is probably regulated by several neurotransmitter systems, noradrenaline is one of the most important. Brain noradrenaline is involved in the control of attention ${ }^{2}$; recently, it has been demonstrated that activation of noradrenergic neurons facilitates behavioural responses to subsequent sensory cues ${ }^{3}$. Noradrenergic neurons are particularly active during high states of arousal, such as those induced by exposure to noise ${ }^{4}$.

The clonidine challenge is an established method of manipulating brain noradrenaline function in humans 5 . Clonidine, an $\alpha$-2-adrenoceptor agonist, in low doses acts presynaptically to decrease noradrenergic cell firing and noradrenaline release; these effects can be blocked by idazoxan, a selective $\alpha$-2-adrenoceptor antagonist ${ }^{6}$. We predicted that lapses of attention would increase following clonidine challenge, and that this effect would be reversed either by exposure to noise or by co-administration of idazoxan.

We conducted a parallel-groups, double-blind study involving challenge with placebo, idazoxan, clonidine and idazoxan + clonidine. Half the subjects were tested in quiet and half were played broadband noise over headphones. Subjects were given a medical examination, a familiarization session, and then a baseline test followed by three post-drug tests. The study was approved by the local ethics committee and conducted with the informed consent of the subjects, 74 males, aged $18-35$ years. Their task was a two-choice reaction time task involving focused attention and selective response to the letters A or B (ref. 7), which was

1. Corcoran, D. W. Q. Jl exp. Psychol. 14, 178-182 (1962)

2. Everitt, B. J., Robbins, T. W. \& Selden, N. R. W. in The Pharmacology of Noradrenaline in the Central Nervous System (eds Heal, D. J. \& Marsden, C. A.) 349-378 (Oxford Univ. Press, 1990).

3. Aston-Jones, G., Rajkowski, J., Kubiak, P. \& Alexinsky, T. J. Neurosci. 14, 4467-4480 (1994)

4. Robbins, T. W. \& Everitt, B. J. in Cognitive Neurochemistry (eds Stahl, S. M. et al.) 135-176 (Oxford Univ. Press, 1987).

5. Glue, P. \& Nutt, D. Psychopharmacology 2, 119-137 (1988)

6. Clifford J. M., Day, M. D. \& Orvin, J. M. Br. J. clin. Pharmac. 14, 99-101 (1982).

7. Broadbent, D. E., Broadbent, M. M. P. \& Jones, J. L. Eur. J. cogn. Psychol. 1, 69-94 (1989).

8. Middleton, H. C., Coull, J. T., Sahakian, B. J. \& Robbins, T. W. J. Psychopharmac. 8, 1-7 (1994).

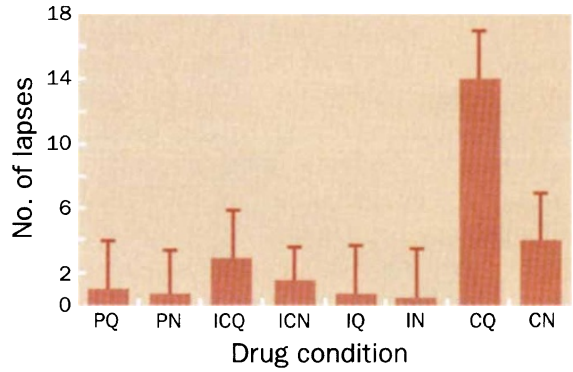

Effects of the different drug and noise conditions on lapses of attention (reaction times > $1,500 \mathrm{~ms}$ ). Scores are adjusted means from an analysis of covariance. Bars, s.e. Drugs were given orally: $40 \mathrm{mg}$ idazoxan; $200 \mu \mathrm{g}$ clonidine; the placebo was lactose. The noise levels were $75 \mathrm{dBA}$ in the noise condition and $50 \mathrm{dBA}$ in the quiet condition. Abbreviations for the various conditions: N, noise; Q, quiet; $\mathrm{P}$, placebo; I, idazoxan; C, clonidine.

adapted to record lapses of attention also (defined as RTs > 1,500 ms). Baseline testing occurred between 09.00 and 10.30 , administration of drugs at 10.30 , and post-drug sessions at 11.00, 13.00 and 15.00 .

The figure shows that the number of lapses of attention was markedly greatest in the 'clonidine, quiet' condition $(P<$ 0.05 ). This effect was reversed by idazoxan and noise, and specific statistical comparisons showed that the clonidine, quiet mean was significantly greater than all the other conditions, which did not differ from one another.

These results clearly demonstrate that central noradrenaline is important in maintaining attention. The effect of clonidine was obtained using a dose that acts selectively at presynaptic receptors to inhibit noradrenaline release ${ }^{8}$, and was fully reversed by idazoxan, an antagonist of these receptors. The reversal of the clonidine effect by noise is consistent with the view that this stimulus increases arousal by increasing noradrenaline release.

\section{Andrew Smith}

\section{David Nutt}

Departments of Psychology and

Psychopharmacology,

University of Bristol,

8 Woodland Road,

Bristol BS8 1TN, UK

\section{Scientific Correspondence}

Scientific Correspondence is intended to provide a forum in which readers may raise points of a scientific character. Priority will be given to letters of fewer than 500 words. Manuscripts can be submitted to either London or Washington.

\section{for life}

SIR - The use of the name Hadean for the first aeon of the Earth's history ${ }^{1}$ has become widespread, but the usage of the term remains variable. In recent years, minerals and rocks roughly 4,000-4,300 million years (4-4.3 Gyr) old have been found on Earth, and work on ribosomal $\mathrm{RNA}^{2}$ has provided insight into the earliest history of life. With this new interest, it becomes necessary to fix the terminology so that the very diverse community of researchers studying the early Earth can use common nomenclature.

The Hadean is the time of Hades; the next aeon, the Archaean, takes its name from the Greek (as in the opening of St John's gospel: "En Archi" or "In the beginning"). The most obvious moment to fix the boundary between the Hadean aeon and the Archaean aeon is at the start of life $\mathrm{e}^{3}$. The recognition of the domains of life $\mathrm{e}^{2}$ allows a more precise definition, however; we should place the end of the Hadean and the start of the Archaean at the time when the last common ancestor (a single cell, the common ancestor to bacteria, archaea and eukarya $)^{2}$, or common ancestral population, of life lived.

This definition is preferable to an arbitrary time-line, both philosophically (stratigraphic definitions should be capable of location in the rock ${ }^{4}$ ) and, more to the point, practically, as the need for the definition lies mainly in the progress of molecular palaeontology.

Intrinsically, it is conceivable that isotopic fingerprints of the earliest living communities exist. For example, photosynthesis, which came later, may have left its isotopic imprint on Archaean carbonates. Until such a fingerprint is established, or a well-calibrated molecular clock is found, our best guess for the time at which the last common ancestor lived is probably roughly $4.0 \pm 0.2 \mathrm{Gyr}$ ago, towards the end of massive bombardment of the planet, and before the start of isotopic fractionation by photosynthesis ${ }^{5}$.

\section{E. G. Nisbet}

Department of Geology,

Royal Holloway College,

University of London,

Egham, Surrey TW2O OEX, UK

\footnotetext{
Cloud, P. C. Trans. Geol. Soc. S. Afr. 79, Annexure, 1-33 (1976).

. Woese, C. R. et al. Proc. natn. Acad. Sci. U.S.A. 87, 4576-9 (1990).

3. Nisbet, E. G. Episodes 14, 327-330 (1991)

4. Hedberg, H. D. International Stratigraphic Guide (Wiley, New York, 1976)

5. Sleep, N. H. et al. Nature 342, 139-142 (1989).
} 